\title{
DO OBJETO PARCIAL AO SIGNIFICANTE FÁLICO: UMA LEITURA LACANIANA DE MELANIE KLEIN
}

FROM THE PARTIAL OBJECT TO THE PHALLIC SIGNIFIER: A LACANIAN READING OF MELANIE KLEIN

DEL OBJETO PARCIAL AL SIGNIFICANTE FÁLICO: UNA LECTURA LACANIANA DE MELANIE KLEIN

\author{
Ariana Lucero* \\ Angela Maria Resende Vorcaro ${ }^{* *}$
}

\begin{abstract}
RESUMO
$\mathrm{O}$ artigo pretende retomar a leitura que Jacques Lacan faz da teoria kleiniana. Partiremos da crítica ao seio como primeiro objeto das relações objetais até chegarmos ao falo intervindo desde o início nas relações da mãe com a criança. Procuraremos mostrar como a tese lacaniana a respeito do significante fálico encontra suporte nas observações de Melanie Klein, que fornecem elementos para pensar no pênis do pai como primeiro substituto do seio materno, atuando, desde o princípio, no interior do corpo materno. A precocidade do complexo de Édipo é, então, abordada em ambos os autores, com o intuito de evidenciar a ação do significante nos primórdios da constituição subjetiva. $\mathrm{O}$ que nos leva a interrogar, por fim, se a substituição da relação de objeto pela incidência do significante esgota a questão do objeto na psicanálise.
\end{abstract}

Palavras-chave: Relação de objeto. Falo. Significante. Melanie Klein. Lacan.

\begin{abstract}
This article intends to take up the Lacanian reading of Melanie Klein. Starting from Lacan's critique of Klein's postulation of the breast as the first object in objectal relationship up to the phallus and its intervention since the beginning of the mother-child relationship. We aim to show at what degree the Lacanian thesis concerning the phallic signifier is backed up by Melanie Klein's considerations regarding the role played by the father's penis - perceived by the child as being within the maternal body - as the first substitute of the maternal breast. Furthermore, the authors' thoughts

\footnotetext{
Texto recebido em 18 de agosto de 2015 e aprovado para publicação em 15 de setembro de 2016.

Pós-doutora em Psicologia Institucional pela Universidade Federal do Espírito Santo (UFES), doutora em Psicologia pela UFMG (área de concentração: Estudos Psicanalíticos), professora no Departamento de Psicologia da UFES. E-mail: luceroariana@ yahoo.com.br.

* Doutora em Psicologia Clínica pela PUC São Paulo, professora do Departamento de Psicologia da Universidade Federal de Minas Gerais (UFMG), membro da Association Lacanienne Internationale. Autora dos livros "Crianças na psicanálise" (1999) e "A criança na clínica psicanalítica" (2004), ambos publicados pela Companhia de Freud, psicanalista. E-mail: angelavorcaro@ uol.com.br.
} 
on the precocity of the Oedipus' complex is taken into account, in order to put in evidence the action of the signifier in the early stages of mental constitution. Lastly, the article debates the consequences brought forth by the replacement of the object relation paradigm for that of the signifier incidence.

Keywords: Object relation. Phallus. Signifier. Melanie Klein. Lacan.

\section{RESUMEN}

El artículo pretende retomar la lectura de la teoría kleiniana que realiza Jacques Lacan. Partiremos de la crítica al seno como primer objeto de las relaciones objetales hasta llegar al falo interviniendo desde el comienzo de las relaciones de la madre con el niño. Procuraremos mostrar de qué modo la tesis lacaniana a respecto del significante fálico encuentra soporte en las observaciones de Melanie Klein, que ofrecen elementos para pensar en el pene del padre como primer substituto del seno materno, actuando, desde el principio, en el interior del cuerpo materno. La precocidad del complejo de Edipo es, por lo tanto, abordada en ambos autores, con el propósito de evidenciar la acción del significante en el comienzo de la constitución subjetiva. Lo que nos lleva a preguntar, para finalizar, si la substitución de la relación de objeto por la incidencia del significante agota la cuestión del objeto en el psicoanálisis.

Palabras-clave: Relación de objeto. Falo. Significante. Melanie Klein. Lacan.

s referências a Melanie Klein aparecem em quase todos os seminários
iniciais de Lacan e mesmo em etapas posteriores de seu ensino. Em um
artigo anterior (Lucero \& Vorcaro, 2017), abordamos a releitura que Lacan faz do caso Dick, de Melanie Klein, no contexto de seu primeiro seminário. Neste trabalho, iremos nos deter, inicialmente, em $O$ Seminário, livro 4: a relação de objeto (Lacan, 1956-1957/1995)1', recorrendo aos Seminários 5 e 6 (Lacan, 1957-1958/1999; 1958-1959/2013) sempre que vislumbrarmos a discussão sobre o objeto/significante fálico. Esse trajeto permitirá passar da crítica ao seio como objeto parcial ao reconhecimento do falo como intervindo desde o início das relações objetais como significante.

Juntamente com Anna Freud, Melanie Klein foi uma das inspiradoras da Escola das Relações de Objeto (Object-Relations School) (Roudinesco \& Plon, 1998, p. 552). De acordo com Laplanche e Pontalis (2004), "A noção do objeto parcial está no centro da reconstrução que ela [Melanie Klein] apresenta do

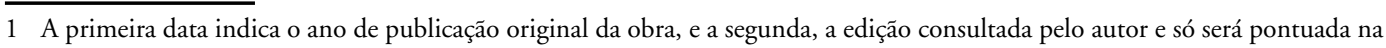
primeira citação da obra no texto. Nas seguintes, será registrada apenas a data de publicação original. 
universo fantasístico da criança" (p. 326), diferentemente da forma como Freud (1915/2004, p. 149) concebia o objeto na psicanálise: o objeto é o elemento mais variável na pulsão e não está originariamente vinculado a ela, sendo-lhe acrescentado em razão de sua aptidão para propiciar a satisfação.

Ao se propor a tratar da questão da relação de objeto no Seminário ${ }^{2}$, Lacan (1956-1957, p. 9) justifica sua escolha por meio do argumento de que "a evolução histórica da psicanálise, ou o que se chama assim" deu a esse tema uma "posição central quanto à teoria e à prática" psicanalíticas. Como lembra Miller (1995), "O Seminário IV está animado por uma luta teórica e ideológica sobre a questão do objeto em psicanálise” (p. 87). O ponto de partida dessa discussão é a publicação (por antigos colegas de Lacan, membros franceses da IPA) da obra coletiva La psychanalyse d'aujourd'hui (Nacht, 1956) ${ }^{4}$, livro ao qual Lacan (1958a/1998) irá se referir

Unicamente pela simplicidade ingênua com que nele se apresenta a tendência a degradar, na psicanálise, a direção da análise e os princípios de seu poder. Obra de difusão para o exterior, sem dúvida, mas também, no interior, de obstrução. Assim, não citaremos seus autores, que não intervêm aqui por nenhuma contribuição propriamente científica (p. 649).

Lacan (1956-1957) relata que, no referido livro, vê-se, "do começo ao fim, a relação de objeto valorizada e promovida de uma maneira que, sem dúvida, nem sempre é muito satisfatória no sentido do articulado, mas cuja monotonia, uniformidade, é de certo surpreendente" (p. 11). Ele se diz espantado com o fato de alguns psicanalistas centrarem sua experiência clínica inteiramente em torno da relação de objeto, sem que haja uma teoria consistente por trás dessa prática e destaca, como citado, a monotonia e uniformidade dos esquemas preconcebidos de desenvolvimento do sujeito e da libido usados na explicação de quase todos os casos clínicos. Vale lembrar que tais esquemas se fundamentavam, em sua maioria, no quadro de desenvolvimento da libido proposto por Abraham (1924/1970), que contemplava a delimitação de seis estágios (fase oral primária e tardia, fase sádico-anal primária e secundária, fase genital e fase de acabamento genital), acompanhados de suas respectivas ligações objetais e psicopatologias: esquizofrenia, psicose maníaco-depressiva, paranoia, neurose obsessiva, histeria, até chegar à normalidade. Assim, grosso modo, seria possível remeter qualquer neurose obsessiva a uma fixação na fase sádico-anal secundária, fornecendo explicações para a sintomatologia do paciente no escopo do que se delimita como típico dessa fase de desenvolvimento (por exemplo, ambivalência de

2 O livro, organizado por Sacha Nacht, foi publicado pela PUF (Paris), em 1956. Ele conta com um prefácio escrito por Ernest Jones e artigos dos seguintes autores: Sacha Nacht, Maurice Bouvet, Serge Lebovici, Pierre Mâle, J. A. Favreau, F. Pasche, Jean Mallet e René-Raphaël Held. 
sentimentos, necessidade de contenção, arrumação etc.) e buscando que ele evolua para relações objetais "mais normais" (e genitais).

De acordo com Roudinesco e Plon (1998, pp. 553-554), as veementes críticas de Lacan se dirigiam aos clínicos da escola francesa, em especial a Maurice Bouvet, e poupavam os autores ingleses, a quem admirava e em quem se inspirava. Afinal, a fórmula acima não era adotada pelos psicanalistas atentos à fala de seus pacientes e à teoria psicanalítica, e o próprio Abraham não a usava de forma ingênua e impensada. Mesmo sendo discípula de Karl Abraham, Melanie Klein não se restringiu às suas explicações e fundou um sistema de posições (esquizoparanoide e depressiva) que independia do desenvolvimento libidinal.

É nesse contexto de questionamento das teorias das relações objetais pautadas no desenvolvimento, portanto, que Lacan elabora uma concepção própria da relação de objeto, "a meio caminho entre o freudismo clássico, o kleinismo e as teses de Winnicott" (Roudinesco \& Plon, 1998, p. 554). Neste artigo, nós nos restringiremos a mostrar como a discussão das teses kleinianas contribuiu para a formulação lacaniana do objeto, ${ }^{3}$ na esteira da afirmação de Rabinovich (2009) de que "os erros de Klein, suas confusões, seus esquecimentos, suas parcializações de Freud foram um guia fundamental para a elaboração por parte de Lacan de seu próprio conceito de objeto" (p. 81). Verificaremos até que ponto Lacan se serve e acompanha os desenvolvimentos da teoria kleiniana bem como em que momento surge uma concepção inteiramente nova e original do problema da relação de objeto nos primórdios da constituição psíquica. Para tanto, intercalaremos retomadas da obra de Melanie Klein com comentários de Lacan, no intuito de traçarmos a maneira como se colocou a questão da delimitação do objeto na psicanálise para o autor francês (não esgotada com o significante fálico).

Segundo Klein (1955): “Todos os aspectos da vida mental estão intimamente ligados a relações de objeto” (p. 167). Estas teriam início com a primeira experiência de alimentação, de tal forma que, no psiquismo do bebê, a mãe aparece primariamente como um seio bom e um seio mau cindidos, uma vez que a sua relação com ela implica a internalização de um seio devorado (e, portanto, devorador) e de um seio que satisfaz. Essa situação decorre da ação dos mecanismos de introjeção e projeção, que operariam lado a lado desde o início da vida, fazendo com que situações externas e internas estivessem sempre interdependentes.

Lacan (1956-1957) sustenta que essa simetria perfeita entre introjeção e projeção, o fato de que o "objeto está perpetuamente numa espécie de movimento que o faz passar de fora para dentro, para ser, em seguida, ejetado de dentro para

3 A influência de Winnicott sobre Lacan foi desenvolvida em outro trabalho (Lucero \& Vorcaro, 2015). 
fora” (p. 177), é um abuso contra o qual se erguerá sua própria teoria. Para ele, se a criança morde a mãe ou fantasia com a mordida, isso não é suficiente para deduzir que ela tenha medo da mordida da mãe, mas "é o eixo essencial daquilo que se trata de demonstrar" (Lacan, 1957-1958, p. 262). Afinal, como surge a compreensão das ações na criança? O significado de certos comportamentos é fantasisticamente preconcebido ou fornecido a posteriori?

Para Klein (1946), o simples ato de sugar o seio já envolve um sadismo e um dano ao objeto que será introjetado, fazendo desse objeto um perseguidor interno e temido. Soma-se a isso o fato de ela supor um impulso destrutivo inato (a pulsão de morte) que é projetado como agressão e, por conseguinte, retorna como agressividade. Quanto ao seio que alimenta e satisfaz, ele também será introjetado e recebido como um objeto bom. Vejamos como a psicanalista sintetiza o que apresentamos até aqui:

Tenho expressado com frequência minha concepção de que as relações de objeto existem desde o início da vida, sendo o primeiro objeto o seio da mãe, o qual, para a criança, fica cindido em um seio bom (gratificador) e um seio mau (frustrador); essa cisão resulta numa separação entre o amor e o ódio. Sugeri ainda que a relação com o primeiro objeto implica sua introjeção e projeção e, por isso, desde o início as relações de objeto são moldadas por uma interação entre introjeção e projeção, e entre objetos e situações internas e externas (Klein, 1946, p. 21).

Este primeiro momento da vida psíquica é descrito por Klein no escopo daquilo que ela denominou posição esquizoparanoide, na qual esse processo de cisão do objeto origina uma ansiedade persecutória por parte do objeto mau que deve ser compensada pelo objeto bom. Ademais, à cisão do objeto corresponde uma cisão do próprio ego - "O ego é incapaz de cindir o objeto, interno e externo, sem que ocorra uma cisão correspondente dentro dele" (Klein, 1946, p. 25) -, donde a necessidade de conter essa fragmentação. Para solucionar esse problema, Klein (1946) coloca como principal objetivo da cisão a dispersão do impulso destrutivo, de modo que apenas o seio frustrador é sentido como fragmentado; o seio gratificador permanece inteiro e se torna responsável pela coesão e integração do ego. Lacan (1957-1958) assinala que, na perspectiva kleiniana, toda a apreensão da realidade é sustentada pela constituição essencialmente alucinatória e fantasística desses primeiros objetos bons e maus: "Chegamos, assim, à ideia de que o mundo do sujeito é construído por uma relação fundamentalmente irreal entre ele e os objetos que não passam do reflexo de suas pulsões fundamentais" (p. 224). Tudo isso fruto da interdependência entre o externo e o interno, construído de forma autônoma na mente do bebê, como se a realidade fosse uma simples extensão (projeção) do que se passa internamente, sem nenhum princípio organizador. 
Pois bem, aparentemente, Klein (1946) se afasta desse mundo fantasístico ao concordar com a hipótese de Winnicott de que "a integração e a adaptação à realidade dependem essencialmente da experiência que o bebê tem do amor e do carinho da mãe" (p. 25). Isto é, conforme se deem as experiências de gratificação e frustração (lembremos que a mãe deve ser apenas suficientemente boa), o bebê tem acesso àquilo que vem do exterior e percebe com mais clareza aquilo que vem do interior. Contudo, no entendimento de Lacan (1957-1958), mesmo que a experiência permita uma demarcação razoável daquilo que nesses objetos pode ser definido como correspondente a certa realidade, mantém-se absolutamente fundamental na teoria kleiniana a trama de irrealidade. Vejamos.

De fato, sob a ótica kleiniana, a progressiva integração do ego e a consequente síntese dos aspectos contrastantes do objeto (bom e mau) não elimina os mecanismos fantasísticos anteriores (como os de projeção, introjeção e cisão). Descobrir que os objetos amado (seio bom) e odiado (seio mau) são, na verdade, um único e mesmo objeto (a mãe como objeto total) não impede que o sujeito tema a internalização do objeto bom e sua destruição, mas acrescenta a isso o sentimento de culpa resultante dos impulsos agressivos que foram projetados contra o objeto amado. Temos aí a intensificação do medo da perda do objeto em todos os sentidos, o que caracteriza a posição depressiva. Klein (1946) assevera:

Não se pode traçar uma divisão clara entre dois estágios do desenvolvimento; além disso, a modificação é um processo gradual e os fenômenos das duas posições [esquizoparanoide e depressiva] permanecem por algum tempo entrelaçados e interagindo em alguma medida (p. 35).

As posições coexistem e, em alguns casos, verifica-se a recorrência do processo de cisão e de manutenção das figuras boas e más separadas. Contudo apenas a posição depressiva prepara o caminho para relações de objeto mais satisfatórias, aquelas que se dão com um objeto total, e não apenas parcial. E talvez seja nesse ponto de sua argumentação que Klein mais se aproxima da tese abrahaminiana de que a evolução do amor objetal deveria ter seu fim na fase genital, com a síntese das pulsões parciais, doravante capazes de investir um único objeto como todo. Nesse nível mais alto da organização da libido, que coincide com a "fase do amor objetal verdadeiro, encontramos sentimentos sociais de um tipo elevado, que regulam a vida instintiva do indivíduo" (Abraham, 1924, p. 155). Assim, o ideal da análise e, de modo geral, da vida de qualquer pessoa, seria atingir esse nível de maturação genital.

Podemos dizer que amar um objeto "como um todo" é um grande passo no desenvolvimento e serve de base para a situação de "perda do objeto amado" (Klein, 1934, p. 306). Klein (1934) explica, efetivamente, que esse processo é influenciado pelo 
Fracasso sentido pelo sujeito (durante o desmame, assim como nos períodos que o antecedem e o seguem imediatamente) em manter seu objeto bom internalizado, isto é, apossar-se dele. Um dos motivos para esse fracasso é a incapacidade de vencer o medo paranoide dos perseguidores internalizados (p. 309 - grifos da autora).

De modo que a cisão do objeto total em objetos parciais não deixa de existir. Assim, novamente surge a ideia de que, "sem dúvida, quanto mais a criança conseguir desenvolver uma boa relação com sua mãe real nesse estágio, maior será a facilidade com que superará a posição depressiva" (Klein, 1934, p. 328) e, por conseguinte, a ameaça de "perda do objeto amado".

A ênfase nas gratificações ou satisfações primordiais bem como nas frustrações que se produzem nos primórdios da vida do sujeito, a partir das relações do sujeito com sua mãe real é alvo das contestações lacanianas. Para Prado Júnior (2003), a concepção da relação objetal em Klein tende a descaracterizar a descoberta freudiana do inconsciente e da fantasia, ao "permanecer prisioneira da oposição clássica entre imaginação e percepção, fantasia e realidade” (pp. 252-253). Há uma divisão estrita entre mundo da fantasia e mundo real em Melanie Klein, que interagem dicotomicamente, visto que o sentimento de ter um seio bom e inteiro depende da quantidade de frustrações que a criança sofre, cabendo à mãe tentar minimizá-las. Parece não se colocar em questão que uma criança bem tratada e bem alimentada possa desenvolver graves psicopatologias, e vemos o ambiente externo se sobrepor ao que pode existir de problemático em qualquer relação com o infantil, seja da criança, seja do próprio adulto.

$\mathrm{Na}$ explicação de Miller (1995), a ideia clássica que estava sendo desenvolvida pela teoria analítica pós-freudiana consistia em conceber a frustração no nível da demanda e da sua satisfação. Assim, o sujeito "pede porque tem fome, pede o objeto que o alimenta, porque tem sede, pede líquidos, pede objetos da necessidade" (Miller, 1995, p. 53). O fato de a demanda não poder ser plenamente satisfeita causaria as frustrações, de fundamental importância para o desenvolvimento do sujeito, tal como trabalhado por Winnicott (1951). Nas palavras de Lacan (1956-1957): "A psicanálise ingressou cada vez mais numa dialética da necessidade e de sua satisfação, à medida que se interessou mais e mais pelos estágios primitivos do desenvolvimento do sujeito" (p. 223). Desse modo, um dos grandes problemas identificados nessa concepção de relação de objeto seria o de tratar a relação mãe-criança com base naquilo que se desenrola na realidade cotidiana: "Toda a ambiguidade da questão levantada em torno do objeto se resume na seguinte: o objeto é ou não o real?” (p. 29).

Lacan (1956-1957) aponta para a nítida distinção, que é feita por Klein, entre o seio real (objeto parcial) e a mãe como objeto total: "Ela distingue realmente os 
objetos parciais, por um lado, e, por outro, a mãe na medida em que se institui como objeto total, e pode criar na criança a famosa posição depressiva" (p. 127). $\mathrm{Na}$ sua interpretação, apesar de Klein não evidenciar que esses dois objetos são de natureza diferentes (um é real e serve para a satisfação da necessidade, enquanto o outro é aquele que pode ou não dar o seio), fica claro que a frustração está menos ligada ao seio do que à mãe. Quando a mãe não dá o seio, a criança se frustra. A frustração, para além do objeto real, reporta-se à demanda de amor (não atendida). A frustração não se passa no nível do gozo, da alimentação e da satisfação de uma necessidade, mas na frustração de amor. Nesse ponto, Lacan (1956-1957) assimila à teoria kleiniana sua tese a respeito do dom, mostrando que "existe uma diferença radical entre, por um lado, o dom como signo de amor, que visa radicalmente a alguma coisa outra, um mais-além, o amor da mãe e, por outro lado, o objeto, seja qual for, que venha para a satisfação das necessidades da criança” (p. 127).

Na perspectiva lacaniana, o importante a destacar é que a criança depende da mãe, de um outro, para ter acesso aos objetos (o objeto sozinho não tem valor). Recebê-los é uma prova de amor, um testemunho do dom oriundo da potência materna. Nesse sentido, Lacan (1956-1957) definirá a "frustração" como recusa do dom, visto que o dom é símbolo do amor: "O que está assim em jogo é menos o objeto que o amor de quem lhes pode fazer este dom. O objeto da frustração é menos o objeto que o dom" (p. 101). Visto que a mãe também carece do objeto da satisfação, para ela igualmente perdido, ela só pode oferecer substitutos do dito objeto, desdobrando-se para dar aquilo que não tem. Desde essa época, Lacan (1956-1957) já caracteriza o amor como dar o que não se tem e, por isso, o dom é dom de amor. O dom faz o objeto se evanescer como objeto, posto que "muito mais importante que os objetos da necessidade é a mão que dá. O mais importante da demanda não é o objeto da necessidade, mas o fato de que o Outro responde dando algo" (Miller, 1995, p. 53). O caráter fundamental da relação de amor não implica somente um objeto, e, sim, um ser (Lacan, 19561957, p. 184).

Com efeito, Lacan (1958-1959) nota que é apenas na frustração que nasce a primeira apreensão do objeto, enquanto o sujeito é dele privado. É quando a mãe falha, ausenta-se, deixa de responder no lugar onde é esperada (privação), que ela se torna uma potência capaz de dar ou não o objeto de satisfação. A frustração, portanto, "incide sobre algo de que vocês são privados por alguém de quem poderiam, justamente, esperar o que lhe pediam" (Lacan, 1956-1957, p. 101). Assim todos os objetos que supomos ser da ordem da pura e simples satisfação tornam-se objetos de dom. Por conseguinte, o seio já não é o seio que alimenta, satisfazendo uma necessidade, mas um objeto simbolizado, que tem 
valor significante: ele é objeto do dom de amor do objeto "total" que é a mãe. É apenas na relação da criança com a mãe que o objeto passa a ter importância, isto é, quando o objeto real, o seio, de fato, perdeu sua função natural.

Ora, no sistema kleiniano, o objeto materno total comporta a multiplicidade dos objetos parciais, fragmentados, e é do corpo da mãe que, desde o início, o sujeito quer arrancar os bons e maus objetos com toda sua agressividade. Entre estes objetos, é a própria Melanie Klein quem dá relevo ao pênis do pai por meio do testemunho de seus pequenos pacientes: "Melanie Klein, sem saber o alcance do que ela diz neste momento, toma o partido de dizer que pode haver alguma coisa melhor que o seio da mãe, a saber, o falo. Só que ela não explica por quê. Isso resta misterioso" (Lacan, 1958-1959, p. 264 - tradução nossa). $\mathrm{Na}$ leitura lacaniana de Klein, o falo se introduz como o primeiro substituto do seio na vivência infantil, controlando os impulsos de incorporação e destruição dirigidos aos conteúdos do corpo da mãe (Lacan, 1958-1959, p. 255). Para o autor, Melanie Klein faz do falo, desde o início, o objeto primordial em torno do qual vão girar todos os eventos dos períodos paranoide e depressivo, o que é visível em suas análises. Ele destaca "o fato kleiniano de que a criança apreende desde a origem que a mãe 'contém' o falo" (Lacan, 1958b/1998, p. 700), isto é, ela apreende os objetos primordiais como contidos no corpo da mãe:

Só temos acesso à experiência primitiva da criança com uma luneta, é claro, mas Melanie Klein aproximou-se dela o máximo possível, analisando crianças de três e quatro anos, e nos fez descobrir uma relação com o objeto que se estrutura sob a forma que qualifiquei de império do corpo materno. Não se pode desconhecer que o simples fato de nos mostrar isso já constitui uma contribuição eminente.

Vocês o constatam a propósito do que ela chamou, em suas contribuições, de Édipo ultraprecoce da criança. Os desenhos desta mostram-nos que o império materno comporta em seu interior o que chamei, numa referência à história chinesa, de reinos combatentes - a criança é capaz de desenhar no interior desse campo aquilo que ela identifica como significantes: os irmãos, as irmãs, os excrementos. Tudo isso coabita no corpo materno, tudo já está em seu interior, uma vez que ela também distingue ali o que a dialética do tratamento permite articular como sendo o falo paterno. Este se acharia desde sempre presente, como um elemento particularmente nocivo e particularmente rival em relação às exigências da criança no que concerne à posse do conteúdo do corpo materno (Lacan, 1957-1958, p. 293).

O elemento em jogo desde o início na relação da mãe com a criança é o falo e não o seio. É ele que explica que as relações primitivas sejam conflituosas, pois "nenhuma relação biológica natural é capaz de explicar suas causas" (Lacan, 1957-1958, p. 293). A criança não projeta indefinidamente o que se passa em seu "mundo interno" para a realidade, pois há um elemento externo que 
intervém para significar suas vivências. Ademais, a criança nunca está sozinha com a mãe, já que, diante da mãe, há o significante de seus desejos, o falo. Isso foi dito por Melanie Klein: no interior do corpo materno, no fundo de seu órgão sexual, está o pênis do pai, temido e desejado. A relação da criança com a mãe é, desde sempre, intermediada pelo falo, e é com esse objeto que a criança tem de concorrer para obter o amor de sua mãe. Tendo isso em mente, Lacan (19581959) se pergunta:

Como podemos formular com os elementos algébricos dos quais nos servimos isso de que se trata nessas famosas relaçōes [da criança com o objeto materno nomeadamente]. A partir daí, podemos conceber como se faz a junção com este significante privilegiado do qual tento aqui situar a função (p. 259, tradução nossa).

Nesse momento do ensino lacaniano, a fórmula da fantasia, $\$ \diamond a$, vem como resposta ao problema do objeto de desejo em sua relação ao outro (Lacan, 19581959). O pequeno a dessa fórmula diz respeito, portanto, ao outro especular, com quem a criança se identifica na constituição de seu eu e de sua imagem corporal. No estágio do espelho, a criança necessita de uma imagem do outro para constituir seu eu. Essa imagem do outro não é a forma do corpo do outro, mas uma imagem que o outro devolve à criança de seu próprio corpo. Cabe lembrar que essa imagem não corresponde ao corpo real do bebê, mas é uma construção fantasística que antecipa um sujeito capaz de fazer coisas para as quais ele ainda não está biologicamente preparado. Exemplo disso é o fato de segurarmos a criança em postura ereta diante do espelho, quando ela não pode sozinha sustentar seu corpo em pé ou andar. Por isso que, para isso, nem mesmo é preciso um espelho. Basta um olhar, um gesto, uma palavra. A criança se identifica a uma certa posição de seu ser nos poderes da mãe, e aí situamos a importância das relaçôes com o objeto materno: pelo outro, se estabelece a relação com as próprias pulsóes. A dinâmica pulsional não se estabelece a partir de uma relação biunívoca entre mundo interno e mundo externo, fantasia e realidade. É a passagem pelo Outro, submetido ao significante fálico, que significa o que acontece com o sujeito, fornecendo inclusive uma imagem antecipatória ideal de esse ser ainda incompleto e incapaz de autonomia. Sobre esse jogo de engodo que Lacan (1957-1958) fundamentará o complexo de Édipo, a partir das posições que o falo ocupa no desejo da mãe.

Dessa maneira, não haveria, para Lacan (1958-1959, pp. 261-262), nenhuma identificação ideal que se daria com a mãe como totalidade. A essa primeira identificação simbólica possibilitada pelo Outro, seguir-se-ia uma identificação imaginária, característica da fase do transitivismo, ${ }^{4}$ na qual o sujeito pode se identificar por meio de seu semelhante. Essa identificação pode ser exemplificada pela situação de invidia descrita por Santo Agostinho (2008): "Vi e observei

4 Sobre o transitivismo, ver Bergès e Balbo (2002) e Jerusalinsky (2011, pp. 141-145). 
uma [criança], cheia de inveja, que ainda não falava e já olhava, pálida, de rosto colérico, para o irmãozinho de leite" (p. 30). O sujeito se reconhece nesse outro que está possuindo o seio materno e, "deste fato, o sujeito toma consciência do objeto do desejo enquanto tal” (Lacan, 1958-1959, p. 263, tradução nossa).

O seio somente se torna objeto de desejo se puder ser desejado por outro. Só se deseja porque o outro deseja, de modo que não há um objeto exclusivo que pertença unicamente ao sujeito ou à mãe. $\mathrm{O}$ objeto do desejo só tem valor pelo que representa em uma determinada relação, ou seja, depende do significante fálico. Assim, ao constatar que a mãe não é a detentora do objeto do desejo e que, muitas vezes, é também isso que ela busca, afastando-se do filho em prol de outros interesses, desfaz-se a fantasia da mãe como objeto total. Para Lacan (1958-1959, p. 263), é isso que justifica que chamemos de "fase depressiva" o reconhecimento da mãe como totalidade, que, ao contrário do que se esperava, não contém todos os objetos. A própria Melanie Klein afirmava que a posição depressiva é essencial na experiência de "perda do objeto amado", e tal perda não se refere a nenhuma vivência de ausência da mãe, mas ao reconhecimento de que a essa mãe também falta um objeto.

De acordo com Lacan (1958-1959), "O ser humano não tem nenhuma possibilidade de aceder a uma experiência de totalidade, ele é dividido, rasgado, e nenhuma análise lhe restitui esta totalidade" (p. 262, tradução nossa). Essa alusão à finalidade da análise novamente nos remete a Abraham e a certos pressupostos que o psicanalista francês visava a combater. Para ele, o sujeito, quer se trate da mãe ou do bebê, é sempre um sujeito castrado, barrado, cindido pela ação do significante, tal como escrito na fórmula da fantasia:

Como tal, $\$ \diamond$ a significa isto (é conforme o sujeito está privado de alguma coisa dele mesmo que tomou valor do significante mesmo de sua alienação, essa alguma coisa é o falo) é conforme o sujeito está privado de algo ligado à sua própria vida por ter tomado valor daquilo que o vincula ao significante, que um objeto particular se torna objeto de desejo (Lacan, 1958-1959, p. 387, tradução nossa).

O falo é o significante que se apresenta no horizonte de toda relação de objeto:

De fato, o que se chama relação [relation] de objeto é sempre relação [rapport] do sujeito, não a objetos, como se diz, mas a significantes da demanda [. . .] Porquanto a demanda, ela, permanece fixa, pode-se articular os modos do aparelho significante respondendo aos diferentes tipos (oral, anal e outros) da demanda, de uma maneira que apresenta, com efeito, uma espécie de correspondência clínica com relação [rapport] ao objeto. Não deixa de haver, contudo, um grande inconveniente em confundir o que é relação [rapport] ao significante com aquilo que é relação [rapport] ao objeto (Lacan, 1958-1959, pp. 368-369, tradução nossa). 
Lacan introduz a importância do significante nas relações objetais, visto que é ele que propicia a equivalência entre coisas distintas e a substituição contínua de uma coisa por outra. Isso é possível porque, no fim das contas, não há objeto que responda pelo desejo. A ideia de que o objeto é, para sempre, um objeto perdido, devido à ação mesma do significante, substitui a primariedade das relações objetais por uma primazia do significante. É a "falta do objeto" que move a cadeia significante, significando as relações objetais conforme as demandas estabelecidas culturalmente no curso do desenvolvimento. Com as demandas oral de alimentar-se ou anal de controlar seus esfíncteres, o sujeito tem acesso a desejos efêmeros e mutáveis. Rabinovich (2005, p. 11) afirma que Lacan elege o falo como "regulador do desenvolvimento", visto que é o colorido fálico que fará dos objetos mais ou menos interessantes e atraentes. Isso é visível nos textos kleinianos que abordam as análises de crianças por meio de desenhos e brincadeiras: é sempre o falo que está em questão, apesar de a autora confundir seu valor significante diferencial com seu conteúdo imaginário. No afã de interpretar as manifestaçôes infantis de acordo com o complexo de Édipo freudiano, a psicanalista não percebe que é o próprio complexo de Édipo que ali se estrutura:

Isso é o que nos parece evidente ao examinarmos atentamente a economia do que Melanie Klein articula como acontecendo no nível do Édipo precoce. Essa expressão não é outra coisa senão uma contradição dos termos - é uma maneira de dizer o Édipo pré-edipiano. É o Édipo antes que qualquer dos personagens do Édipo tenha aparecido. Os significantes interpretativos de que ela se serve para dar nome às pulsões com que se depara, ou que acredita se deparar na criança, os significantes dela mesma, implicam toda a dialética de que se trata na origem (Lacan, 1957-1958, p. 318, grifos do autor).

O Édipo independe do pai e da mãe reais. A precocidade do complexo de Édipo se pauta no papel do significante como elemento que intervém de imediato na relação da mãe com o bebê. Pelo significante que "entramos na atividade simbólica propriamente dita, naquela que faz do ser humano um ser falante, o que definirá toda sua relação ulterior ao nosso objeto" (p. 265 - tradução nossa). Isso é bem diferente de afirmar que o mundo externo é uma projeção do mundo interno. A relação imaginária do sujeito com o mundo, fundada sobre as projeçôes dos conteúdos internos, tal como define Melanie Klein, não pode ser garantia de nenhuma relação com a realidade externa. A passagem de dentro para fora e de fora para dentro não se dá apenas de forma especular: "É preciso introduzir a ideia de que o exterior, para o sujeito, é inicialmente dado não como alguma coisa que se projeta a partir de seu interior, de suas pulsões, mas como a sede, o lugar onde se situa o desejo do Outro, e onde o sujeito tem que 
ir encontrá-lo" (Lacan, 1957-1958, p. 283).

Mesmo no estágio do espelho, intervém um terceiro elemento e a incidência do significante sob a forma do falo, do desejo do Outro, sobrepõe-se definitivamente às consideraçôes sobre o imaginário fantasístico ou sobre um real restrito a uma concepção da realidade empírica. Nesse sentido, o "império do corpo materno", ao contrário do que sustenta Klein, não pode ser dado a priori, mas deve ser construído a partir da projeção retroativa de todos os objetos imaginários no corpo da mãe. As fantasias não são inatas. Elas devem, antes, ser interpretadas retroativamente: "É na construção do sujeito que vamos vê-las se reprojetar no passado, a partir de pontos que podem ser muito precoces" (Lacan, 19561957, p. 66). Se uma criança de 2 anos pode ter a impressão de encontrar no corpo da mãe os "objetos reprojetados retroativamente", isso não quer dizer que as fantasias sejam primárias. Para o psicanalista francês, é o fato de haver uma ordem simbólica que permite a formação dessas fantasias. É também devido a ela que Melanie Klein consegue antever a estrutura edipiana em crianças tão novas: "Tudo se passa como se, quanto mais nos aproximássemos da origem, mais o complexo de Édipo estivesse ali, articulado e pronto para entrar em ação" (Lacan, 1956-1957, p. 114).

No seguimento de seu ensino, Lacan continua às voltas com o problema da relação entre mundo externo e mundo interno, fantasia e realidade, e é nesse âmbito que seu conceito de objeto $a$ virá a ser formulado. Neste artigo, tentamos demonstrar como a primazia do simbólico em Lacan lhe fornece instrumentos para reler algumas teses kleinianas. Contudo o significante fálico não responde pelo problema do objeto na psicanálise. As categorias da "falta de objeto" (privação, frustração e castração) cumprirão provisoriamente essa função até que uma nova concepção de objeto seja elaborada. Alguns autores defendem que o objeto $a$ da fantasia contempla uma definição lacaniana do objeto (Roudinesco $\&$ Plon, 1998, p. 554). De nossa parte, acreditamos que a formulação do objeto $a$ só foi possível levando-se em consideração os três registros do funcionamento psíquico (real, simbólico e imaginário), o que ocorreu no Seminário 10 (19621963/2005). Sem entrarmos nos pormenores dessa questão, que exigiria formulações que escapam ao escopo deste trabalho, ${ }^{7}$ podemos concluir dizendo que, para além da concepção lacaniana de objeto (como falta de objeto), Melanie Klein foi essencial na delimitação do falo como significante central para a constituição subjetiva

7 A tese de Lucero (2015), orientada por Angela Vorcaro, dedica-se a abordar com mais profundidade este tema. 


\section{REFERÊNCIAS}

Abraham, K. (1924). Breve estudo do desenvolvimento da libido, visto à luz das perturbações mentais. In K. Abraham Teoria psicanalitica da libido. Rio de Janeiro: Imago, 1970.

Agostinho (Santo) (2008). Confissões. Bragança Paulista: São Francisco.

Bergès, J. \& Balbo, G. (2002). Jogos de posiçôes da mãe e da criança: ensaio sobre o transitivismo. Porto Alegre: CMC.

Freud, S. (1915). Pulsões e destinos da pulsão. In L. Hanns (Trad.), Escritos sobre a psicologia do inconsciente (Vol. 1, pp. 133-173). Rio de Janeiro: Imago, 2004. (Publicado originalmente em 1915).

Jerusalinsky, J. (2011). A criação da criança: brincar, gozo e fala entre a mãe e o bebê. Salvador: Ágalma.

Klein, M. (1934). Uma contribuição à psicogênese dos estados maníaco depressivos. In Amor, culpa e reparação. (pp. 301-329). Rio de Janeiro: Imago, 1996.

Klein, M. (1946). Notas sobre alguns mecanismos esquizoides. In Inveja $e$ gratidão. (pp. 17-43). Rio de Janeiro: Imago, 1991.

Klein, M. (1955). A técnica psicanalítica através do brincar: sua história e significado. In Inveja e gratidão. (pp. 149-168). Rio de Janeiro: Imago, 1991.

Lacan, J. (1956-1957). O seminário, livro 4: a relação de objeto. Rio de Janeiro: Jorge Zahar, 1995. (Proferido originalmente em 1956-1957).

Lacan, J. (1957-1958). O seminário, livro 5: as formaçôes do inconsciente. Rio de Janeiro: Jorge Zahar, 1999. (Proferido originalmente em 1957-1958).

Lacan, J. (1958a). A direção do tratamento e os princípios de seu poder. In J. Lacan. Escritos. (pp. 591-652). Rio de Janeiro: Jorge Zahar, 1998. (Publicado originalmente em 1958).

Lacan, J. (1958b). A significação do falo. In J. Lacan. Escritos. (pp. 692-703). Rio de Janeiro: Jorge Zahar, 1998. (Publicado originalmente em 1958).

Lacan, J. (1958-1959). Le séminaire, livre 6 : le désir et son intérprétation. Paris : Éditions de La Martinière et Le Champ Freudien, 2013. (Proferido originalmente 1958-1959). 
Lacan, J. (1962-1963). O seminário, livro 10: a angústia. Rio de Janeiro: Jorge Zahar, 2005. (Proferido originalmente em 1962-1963).

Laplanche, J. \& Pontalis, J.-B. (2004). Vocabulário da psicanálise. São Paulo: Martins Fontes.

Lucero, A. (2015). Relação de objeto e constituição subjetiva: consideraçôes sobre o objeto a em Jacques Lacan. (Tese de Doutorado). Universidade Federal de Minas Gerais, Faculdade de Filosofia e Ciências Humanas, Belo Horizonte.

Lucero, A. \& Vorcaro, A. (2015). O objeto transicional de Winnicott na formação do conceito de objeto a em Lacan. Natureza Humana, 17(1), 1532. Recuperado a partir de http://pepsic.bvsalud.org/scielo.php?script=sci_ arttext\&pid=S1517-24302015000100002\&lng=pt\&tlng=pt

Lucero, A. \& Vorcaro, A. M. R. (2017). Lacan leitor de Melanie Klein: o caso Dick em questão. Psicologia: Teoria e Pesquisa, 33, 1-8. Recuperado a partir de https://dx.doi.org/10.1590/0102.3772e3348.

Miller, J.-A. (1995). A lógica na direção da cura. Belo Horizonte: Seção Minas Gerais da EBP do Campo Freudiano.

Nacht, S. (Org.). (1956). La psychanalyse d'aujourd'hui. Paris: PUF.

Prado Junior, B. (2003). Lacan: biologia e narcisismo ou A costura entre o real e o imaginário. In V. Safatle (Org.), Um limite tenso: Lacan entre a filosofia e a psicanálise. (pp. 235-254). São Paulo: Unesp.

Rabinovich, D. (2005). A significação do falo: uma leitura. Rio de Janeiro: Cia. de Freud.

Rabinovich, D. (2009). O conceito de objeto na teoria psicanalítica. Rio de Janeiro: Cia. de Freud.

Roudinesco, E. \& Plon, M. (1998) Dicionário de Psicanálise. Rio de Janeiro: Jorge Zahar.

Winnicott, D. W. (1951). Objetos transicionais e fenômenos transicionais. In D. W. Winnicott. O brincar e a realidade. (pp. 13-44). Rio de Janeiro: Imago, 1975. 